REVISIÓN

Rev Obstet Ginecol Venez. 2020; 80 (4):332-342

https://doi.org/10.51288/00800410

\title{
Manejo del cáncer de ovario durante el embarazo
}

\author{
Dr. Eduardo Reyna-Villasmil ${ }^{1}$
}

\section{RESUMEN}

Los tumores malignos ginecológicos más comunes durante el embarazo son el cáncer de cuello uterino y los tumores malignos de ovario. Durante el embarazo, el examen ginecológico es limitado y la tasa de diagnósticos erróneos es mayor. Aunque la aparición de tumores ováricos durante el embarazo es relativamente común, la mayoría de ellos son funcionales y se resuelve espontáneamente. El tratamiento durante el embarazo está relacionado con factores como tamaño del tumor, tipo histológico, edad gestacional, afectación de los ganglios linfáticos y disposición de las mujeres para continuar el embarazo. En los tumores malignos en etapa inicial, la cirugía debe planificarse preferiblemente luego de las 16 semanas de embarazo y la quimioterapia se puede administrar desde el segundo trimestre como en pacientes no embarazadas. El pronóstico no está afectado por el embarazo. La resultante de la embarazada con cáncer de ovario es similar a las pacientes no embarazadas.

Palabras clave: Cáncer de ovario, Embarazo, Manejo, Diagnostico, Tratamiento.

\section{SUMMARY}

The most common gynecological malignancies during pregnancy are cervical cancer, followed by malignant ovarian tumors. During pregnancy, gynecological examination is limited and the rate of misdiagnosis is higher. Although the appearance of ovarian tumors during pregnancy is relatively common, most of them are functional and resolve spontaneously. Treatment during pregnancy is related to factors such as tumor size, histological type, gestational age, lymph node involvement and willingness of women to continue the pregnancy. In early-stage malignant tumors, surgery should be planned preferably after 16 weeks of pregnancy and chemotherapy can be administered from the second trimester as in non-pregnant patients. Prognosis is not affected by pregnancy. The result of pregnant woman with ovarian cancer is similar to non-pregnant patients.

Keywords: Ovarian cancer, Pregnancy, Management, Diagnosis, Treatment.

\section{INTRODUCCIÓN}

Los tumores ováricos representan un amplio espectro de lesiones con morfología y resultados clínicos totalmente distintos. Las potenciales neoplasias diagnosticadas incluyen desde quistes del cuerpo lúteo funcional, el cual es clínicamente insignificante, hasta

\footnotetext{
'Doctor en Medicina Clínica. Especialista en Ginecología y Obstetricia Servicio de Obstetricia y Ginecología. Hospital Central "Dr. Urquinaona". Maracaibo. Estado Zulia. Venezuela.
}

tumores malignos de origen epitelial o no epitelial. La incidencia de tumores de ovario durante el embarazo se estima en $0,15 \%-5,7 \%(1,2)$.

De los tumores quísticos benignos durante el embarazo, los más comunes son: teratomas maduros (quistes dermoides), cistadenoma, quistes del cuerpo lúteo y quistes endometrioides $(3,4)$. El cáncer de ovario está presente en 1:15000 a 1:32 000 embarazos (3) y representa $3 \%-6 \%$ de todas las neoplasias malignas y $49 \%-75 \%$ de los tumores malignos durante el embarazo (5-7). Las neoplasias malignas ováricas no 
epiteliales son menos frecuentes, incluyendo aquellos tumores que se originan de los cordones sexuales $(9 \%$ - $16 \%$ de los tumores malignos de ovario, con mayor frecuencia tumor de las células de la granulosa) y tumores de células germinales $(6 \%$ - $40 \%$, la mayoría de los casos, disgerminoma) $(5,6)$.

Los tumores ováricos malignos durante el embarazo son generalmente asintomáticos $(70 \%-90 \%$ de los casos) y rara vez producen síntomas de abdomen agudo, que se produce como resultado de rotura o torsión del tumor (2). La mayoría de los tumores malignos, tanto epiteliales como no epiteliales, se diagnostican en el primer trimestre del embarazo (8-11). El embarazo no tiene efectos adversos en el curso clínico del cáncer de ovario y el pronóstico es similar al de mujeres no embarazadas (12).

\section{DIAGNÓSTICO DE TUMORES OVÁRICOS DURANTE EL EMBARAZO}

Ultrasonido

La mayoría de los tumores de ovario es diagnosticada de forma accidental durante el primer trimestre del embarazo. El ultrasonido permite determinar las siguientes características del tumor: origen, ubicación, tamaño, estructura interna y clasificación en una de las cinco categorías (quístico, sólidoquístico, multiquístico, sólido-multiquístico y sólido) (8).

Es recomendable realizar la evaluación doppler para determinar el mapa vascular del tumor (13). No existen parámetros de categorización neoplásica para la evaluación de riesgos en estudios de ultrasonido en embarazadas. Las siguientes características pueden sugerir malignidad del tumor: tamaño (diámetro mayor de 5-6 cm), características morfológicas y presencia de lesiones extraováricas (14).

\section{Resonancia magnética nuclear}

Es una prueba complementaria recomendada cuando la evaluación ecográfica presenta resultados ambiguos, los cuales son insuficientes para tomar cualquier decisión terapéutica. Además, facilita la diferenciación entre miomas degenerativos, tumores endometrioides, edema ovárico y tumores malignos $(12,15,16)$. Aunque el uso del agente de contraste gadolinio está permitido a partir del segundo trimestre, la Administración de Alimentos y Medicamentos (FDA), de Estados Unidos, lo considera en la categoría $\mathrm{C}$ por lo que debe tenerse en cuenta sus efectos teratogénicos y potencialmente tóxicos reportados en estudios animales, resultando en desarrollo de fibrosis sistémica y nefrogénica en el feto. Los beneficios del uso de agentes de contrastes en el diagnóstico de tumores anexiales (diferenciación de áreas sólidas y quísticas) generalmente se pueden lograr con la ecografía convencional y, especialmente, con el uso de doppler (15).

Tomografía computada

No debe utilizarse en embarazadas debido al efecto teratogénico de la radiación ionizante. Aunque la dosis absorbida por el feto durante la evaluación abdominal es insuficiente para alcanzar los efectos adversos de la radiación (que ocurren al alcanzar un umbral determinado), se deben recordar los efectos de la radiación estocástica (probabilidad que ocurra es directamente proporcional a la dosis), especialmente sobre las células que se dividen en forma activa, como sucede en embriones/fetos (17). Tales consecuencias incluyen aparición de tumores infantiles secundarios a la irradiación abdominopélvica en embarazadas (18).

Tomografía computada con emisión de positrones

Plantea las mismas preocupaciones que la tomografía computada clásica, ya que es su componente integral. Además, el marcador utilizado es la fluorodeoxiglucosa 


\section{E REYNA-VILLASMIL}

que contiene un radioisótopo. Como no existen estándares de dosimetría en el embarazo, este estudio no debe realizarse en embarazadas (19).

Marcadores tumorales del cáncer de ovario

E1 Ca-125, marcador tumoral comúnmente útil para el diagnóstico de tumores de ovario, tiene uso limitado durante el embarazo. Su concentración aumenta de 30 - $40 \mathrm{UI} / \mathrm{mL}$ el día posterior a la fertilización y alcanzan su valor máximo a los 35 - 60 días del embarazo para luego normalizarse al final del primer trimestre (20). Otra limitación es la baja sensibilidad del marcador en las primeras fases del cáncer de ovario y el aumento de los valores en casos de endometriomas, que a menudo requieren diferenciación durante el embarazo $(21,22)$.

Los marcadores más utilizados en el diagnóstico de tumores germinales, como lo son alfafetoproteína y beta-gonadotropina coriónica humana también aumentan durante el embarazo, lo que limita significativamente su validez diagnóstica. Los valores de referencia habituales para mujeres no embarazadas se alcanzan en 4 - 6 semanas después del parto (2). Las concentraciones de inhibina $\mathrm{B}$, un marcador del tumor de las células de la granulosa, y de deshidrogenasa láctica, uno de los marcadores de tumores germinales, permanecen sin cambios durante el embarazo normal y pueden usarse para diagnosticar y evaluar la evolución de estos tumores (23).

La proteína epididimal humana 4 (HE4) se sobre expresa en cáncer de ovario de tipo seroso, endometrioide y de células claras. Comparado con el Ca-125, está elevada con menor frecuencia en tumores benignos (24). Las concentraciones de HE4 no aumentan, e incluso disminuyen ligeramente, durante el embarazo (25). Considerando su menor sensibilidad, pero mayor especificidad en comparación con Ca-125, en el diagnóstico de cáncer de ovario en mujeres premenopáusicas, la evidencia sugiere la determinación combinada de ambos marcadores tumorales $(26,27)$. Sin embargo, debe recordarse que el valor diagnóstico durante el embarazo sigue siendo desconocido.

Otros marcadores utilizados en la diferenciación de los tumores de ovario cuya concentración no cambia significativamente durante el embarazo son el antígeno carcinoembriogénico y el Ca 19-9 (21).

\section{TRATAMIENTO QUIRÚRGICO}

La cirugía es la base del tratamiento de los tumores malignos de ovario. La decisión de realizar la intervención quirúrgica debe incluir la evaluación del potencial riesgo de malignidad, la probabilidad de urgencias potencialmente quirúrgicas para la madre (torsión, sangrado y ruptura) y el bienestar fetal (28). El algoritmo operativo que se presenta en la figura 1 hace énfasis en los siguientes elementos:

- El tratamiento conservador está justificado en caso de tumores ováricos asintomáticos diagnosticados de forma accidental en la evaluación ecográfica del primer trimestre;

- Los tumores que producen sintomatología o con criterios ecográficos de malignidad deben tratarse quirúrgicamente. La cirugía debe realizarse durante el segundo trimestre;

- Si la imagen ecográfica del tumor ovárico no cumple con los criterios de malignidad, esta debe reevaluarse durante la ecografía prenatal de rutina alrededor de la semana 20 del embarazo;

- La decisión del tratamiento quirúrgico del tumor ovárico, sin evidencia ecográfica de malignidad y detectado durante el tercer trimestre, debe posponerse hasta seis semanas después del parto. 


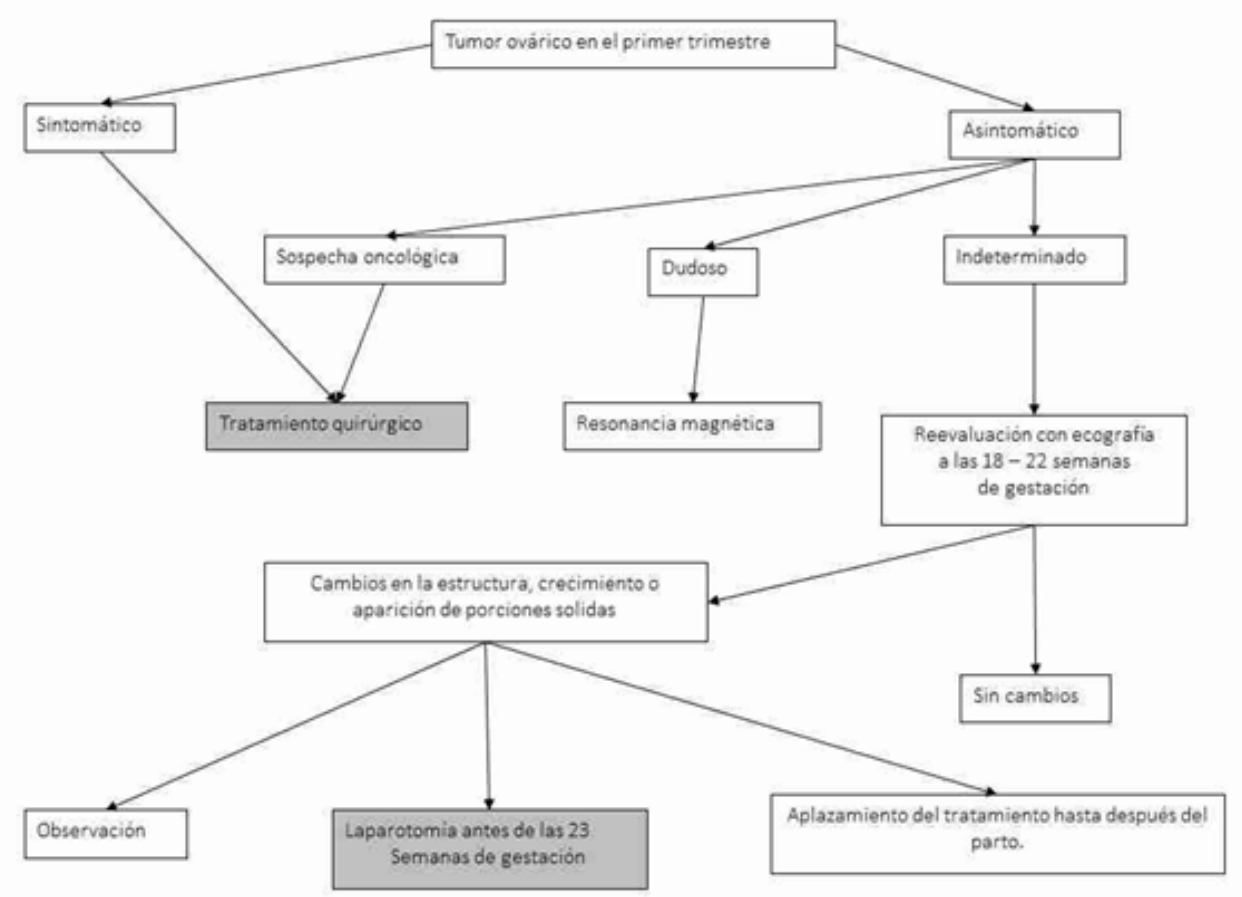

Figura 1. Algoritmo del manejo quirúrgico de los tumores de ovario durante el embarazo.

El cirujano debe tener conocimiento y habilidades suficientes en el tratamiento quirúrgico de los tumores ováricos y conocimiento sobre los cambios fisiológicos del embarazo: aumento de la actividad trombótica, disminución de la actividad anticoagulante, cambios hemodinámicos específicos en el sistema cardiovascular en cada trimestre del embarazo, junto a los cambios anatómicos producidos por el aumento de tamaño del útero (2).

En los casos con sintomatología de abdomen agudo, la decisión sobre el tratamiento quirúrgico debe tomarse de forma inmediata. Al elegir el momento óptimo para la cirugía, debe considerarse la función lútea y el riesgo de aborto espontáneo antes de la semana 13 de embarazo, al igual que la mayor posibilidad de complicaciones como torsión o rotura del tumor o progresión de la neoplasia maligna por retraso en el tratamiento (29).
La elección entre laparotomía o laparoscopia debe tener en cuenta: el tamaño, la ubicación y la posible naturaleza maligna de los cambios ecográficos en el ovario afectado, la edad gestacional, la ausencia o presencia de enfermedades sistémicas que limitan la posibilidad del uso de la laparoscopia y las habilidades del operador.

Para la laparotomía, se recomienda una incisión longitudinal mediana con posibilidad de extenderla por encima de la cicatriz umbilical. Se debe evitar la manipulación y/o presión sobre el útero gestante (30). La laparoscopia se puede realizar de forma segura durante el embarazo siempre que se observen las siguientes condiciones (31):

- Momento de tratamiento óptimo entre las 16 - 20 semana de embarazo; 
- La ubicación de los trocares depende de la edad gestacional y el primer trocar debe colocarse al menos a 3 - 4 centímetros por encima del útero;

- La duración del procedimiento no debe exceder 90 minutos;

- La presión intraabdominal máxima debe mantenerse a 10 - 13 milímetros de $\mathrm{Hg}$;

- La técnica preferida es de entrada abierta sin usar agujas;

- El cirujano debe tener experiencia en procedimientos laparoscópicos en embarazadas.

Se debe realizar la evaluación macroscópica del tumor durante la cirugía. En el caso de tumores con características benignas, se debe tener cuidado y ser lo más conservador posible. En casos de tumores que muestran evidencia de malignidad, se debe intentar extirpar la lesión completamente (considerando la conversión a laparotomía, extirpación del apéndice cecal, epiplón y toma de muestra del líquido peritoneal) (13). Todos los casos deben disponer de forma obligatoria del examen histopatológico intraoperatorio para poder diferenciar entre lesiones malignas y benignas durante la cirugía. El alcance de la cirugía depende del resultado del examen histopatológico y la extensión de las lesiones (figura 2).

Los tumores limítrofes de ovario no son indicación de interrupción del embarazo y pueden tratarse de forma conservadora. La mayoría de estos tumores están limitados a un ovario. Es recomendable durante la cirugía realizar la apendicectomía, tomar muestras de líquido de la cavidad peritoneal o, si esto último

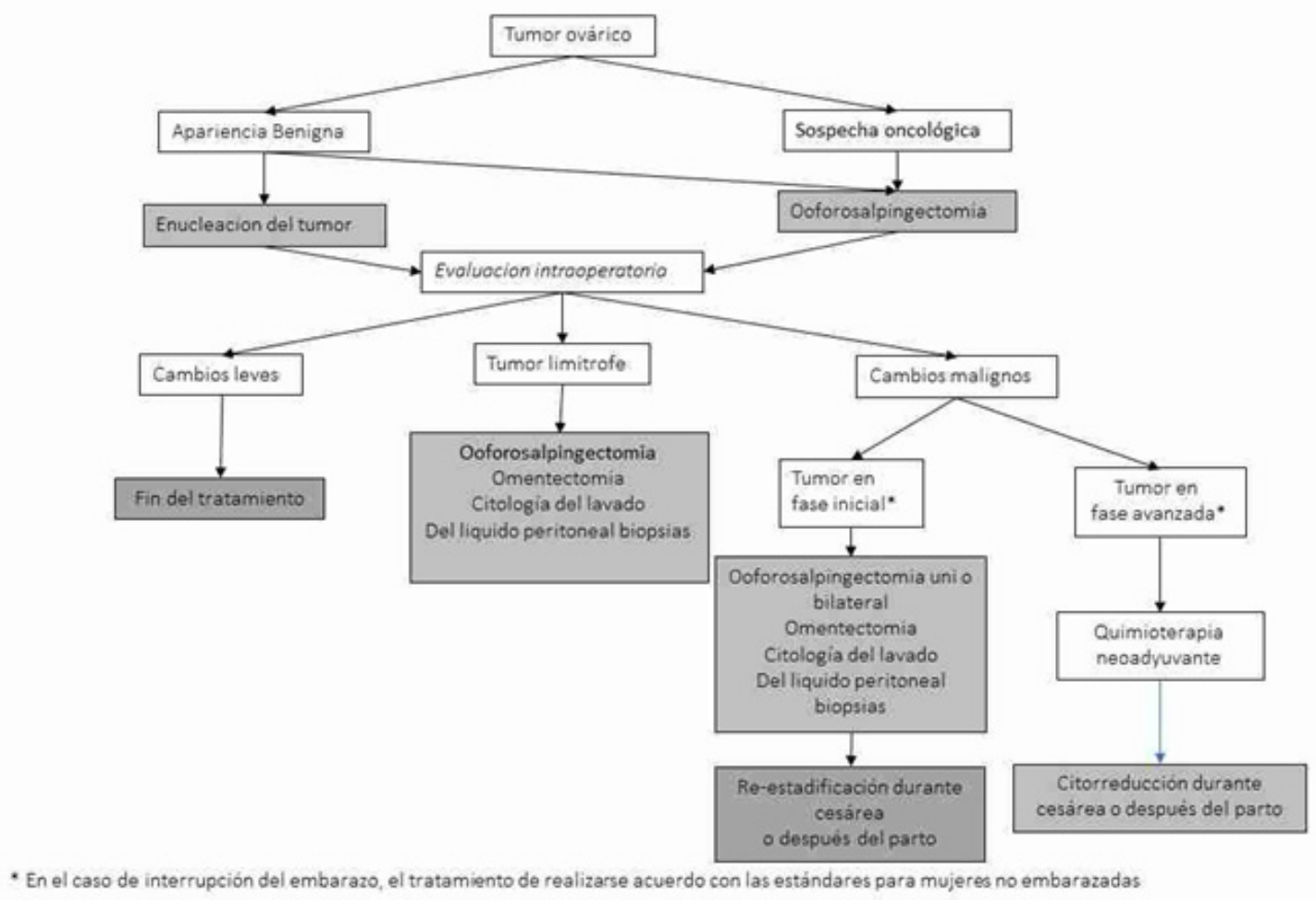

Figura 1. Algoritmo del manejo quirúrgico de los tumores de ovario durante el embarazo. 
no es posible, realizar lavados peritoneales para obtener muestras para la evaluación o examen citológico. En algunos casos también se puede realizar la biopsia peritoneal. En aquellos casos de tumores bilaterales es posible considerar la enucleación del tumor (enucleación del tumor menor y extirpación del anexo con el tumor mayor). Si el diagnóstico de tumor limítrofe es realizado después de la cirugía, se debe realizar una nueva intervención quirúrgica 3 6 semanas después del parto (13). En casos raros de tumores limítrofes de ovario en estadios avanzados establecidos durante la cirugía, la opción es intentar la citorreducción máxima (12). El acceso limitado a la pelvis y, sobre todo, al fondo de saco de Douglas, establece la necesidad de reclasificar después del parto (31).

El tratamiento quirúrgico de los tumores ováricos malignos en embarazadas no difiere de las reglas aplicables a las mujeres no embarazadas. En el cáncer de ovario temprano, el protocolo quirúrgico incluye recolección de líquido de la cavidad/lavado peritoneal para examen citológico, biopsias peritoneales, histerectomía con ooforosalpingectomía bilateral, linfadenectomía pélvica - paraaórtica y apendicectomía en aquellos casos de tumores mucosos. En los casos de tumores de ovario en estadios avanzados, la cirugía implica la máxima citorreducción posible (32).

El tratamiento conservador es posible en las mujeres que desean poder embarazase luego del cáncer de ovario temprano. En el estadio IAG1, la ooforosalpingectomía unilateral, biopsias peritoneales, citología del líquido peritoneal/lavado peritoneal sin linfadenectomía generalmente son suficientes para evitar la recurrencia del tumor (33). Para los estadios IAG2 e IAG3, IB, IC, IIA, los tratamientos son similares, pero deben eliminarse ambos anexos (la afectación del anexo contralateral puede considerarse en el estadio ICG1). La extracción de los ganglios linfáticos en estas etapas debe hacerse solo si los ganglios muestran evidencia de afección neoplásica (12). En este grupo de pacientes, durante la cesárea o después del parto, debe realizarse una nueva estadificación, que incluye histerectomía y linfadenectomía pélvica y paraaórtica $(34,35)$.

En el cáncer de ovario avanzado en embarazadas, la citorreducción óptima generalmente es imposible. El tratamiento durante el embarazo implica biopsia/ extracción del tumor para confirmar el diagnóstico en estos casos. Posteriormente se debe usar quimioterapia neoadyuvante y una nueva cirugía citorreductora luego del parto (36).

En embarazadas, los tumores que se originan de los cordones sexuales generalmente se diagnostican en estadios iniciales. Por lo tanto, el procedimiento de elección es conservador: ooforosalpingectomía unio bilateral, biopsias peritoneales, citología del fluido peritoneal/lavado peritoneal. La linfadenectomía no está recomendada en estos casos. La decisión de reestadificar luego del parto depende de los resultados de las pruebas de imagen y de las concentraciones de marcadores tumorales $(10,11,34)$.

\section{MANEJO PERIOPERATORIO}

Al decidir el tipo de tratamiento quirúrgico, se deben considerar los siguientes factores:

- Si el feto es viable, la cirugía debe realizarse en un centro con instalaciones de neonatología apropiadas para la edad gestacional;

- Si el feto es viable, se debe controlar el bienestar fetal y la actividad contráctil del útero antes y después del procedimiento quirúrgico (37);

- Después de la semana 20 de embarazo, durante la cirugía, es preferible colocar a la paciente inclinada parcialmente hacia el lado izquierdo para evitar el síndrome de la vena cava inferior (30); 
- A las 24 - 34 semanas de embarazo, y al menos 48 horas antes de la cirugía, se debe administrar corticosteroides para acelerar la maduración pulmonar fetal (24 mg de betametasona en 2 dosis con 24 horas de diferencia) (36);

- La suplementación de progesterona está indicada solo después del procedimiento realizado durante el primer trimestre $(2,38)$;

- No se recomienda el uso de rutina (sin actividad uterina confirmada) de tocolíticos durante el periodo perioperatorio (2);

- Se recomienda administrar $300 \mu g$ de inmunoglobulina anti-D a embarazadas con Rh negativo en las siguientes 72 horas a la cirugía (2);

- Se recomienda iniciar profilaxis antitrombótica perioperatoria (enoxaparina $40 \mathrm{mg}$ por vía subcutánea). Si el diagnóstico es de tumor maligno, la anticoagulación debe mantenerse hasta 6 semanas después del parto (39).

\section{TRATAMIENTO ADYUVANTE}

Un grupo importante de las neoplasias ováricas malignas debe ser tratado con quimioterapia adyuvante. Su uso durante el embarazo está asociado a problemas adicionales que no son observados en sujetos no embarazados: riesgo de aborto espontáneo, aparición de defectos fetales y mayor posibilidad de efectos sobre el desarrollo fetal (principalmente hipotrofia) (2). El momento de mayor riesgo de defectos congénitos ocurre a las 2 - 8 semanas del embarazo (40). Por lo tanto, el inicio del tratamiento debe, en la medida de lo posible, posponerse hasta el segundo trimestre. En aquellas situaciones en las cuales este retraso puede afectar en forma marcada el pronóstico de la embarazada, es importante discutir el alcance y efectos del tratamiento con la paciente, incluida la posibilidad de interrupción del embarazo en el primer trimestre del embarazo. Los estándares de quimioterapia para el cáncer de ovario son similares a los utilizados en mujeres no embarazadas. Para los tumores limítrofes no existe indicación de quimioterapia complementaria durante el embarazo (33).

Esquemas de tratamiento

Las pacientes con estadificación IAG1 realizada en forma correcta no necesitan quimioterapia adyuvante y deben ser sometidas a seguimiento riguroso en el tiempo. En las pacientes con estadios IAG2-IIA, el tratamiento adyuvante incluye quimioterapia que consiste en paclitaxel y carboplatino o cisplatino con los siguientes esquemas (31):

- Paclitaxel $175 \mathrm{mg} / \mathrm{m}^{2}$ (infusión de 3 horas) + carboplatino según el aclaramiento estimado y el área bajo la curva;

- Paclitaxel $135 \mathrm{mg} / \mathrm{m}^{2}$ (infusión de 24 horas) + cisplatino $75 \mathrm{mg} / \mathrm{m}^{2}$;

- Docetaxel $75 \mathrm{mg} / \mathrm{m}^{2}+$ carboplatino según el aclaramiento estimado y el área bajo la curva;

- Carboplatino según el aclaramiento estimado y el área bajo la curva.

Los ciclos deben repetirse cada 21 días. El número de ciclos (la cantidad habitual es hasta 6 ciclos) hasta el parto debe ser evaluado según el tiempo entre el inicio de la quimioterapia y la fecha planificada del parto $(31,40)$.

En los casos de cáncer de ovario avanzado durante el embarazo, la quimioterapia puede ser usada como tratamiento adyuvante luego de la citorreducción quirúrgica o quimioterapia neoadyuvante. En ambos casos, los esquemas y dosis de tratamiento son iguales a los de aquellos casos de cáncer temprano. 
La evidencia actual sobre la quimioterapia intraperitoneal no permite evaluar las posibilidades del uso de estos regímenes como una opción terapéutica durante el embarazo (41). Existe poca información y estudios animales que sugiera que los compuestos contra el factor de crecimiento endotelial vascular puedan inhibir la organogénesis y el desarrollo fetal. No obstante, el uso de bevacizumab está contraindicado en el embarazo (19). Tampoco existen datos sobre la seguridad de otras formas de terapias similares durante el embarazo.

Los tumores no epiteliales (disgerminoma de primer grado, teratoma inmaduro en IG1 y tumor de las células de la granulosa en estadios IA y B) no necesitan ser tratados con quimioterapia complementaria. En otros casos, la combinación paclitaxel - carboplatino es el esquema de elección para el tratamiento adyuvante tanto para los tumores germinales como del estroma y los cordones sexuales en el embarazo. Las combinaciones de agentes más estudiadas y utilizadas son paclitaxel $175 \mathrm{mg} / \mathrm{m}^{2}$ (infusión de 3 horas) + carboplatino según el aclaramiento estimado y el área bajo la curva $(31,42-44)$.
El patrón de segunda línea que se repite cada 21 días con patrón de 5 días es: cisplatino $20 \mathrm{mg} / \mathrm{m}^{2}$ en los días 1-5; vinblastina $6 \mathrm{mg} / \mathrm{m}^{2}$ en los días 1 - 2 y bleomicina $30 \mathrm{mg}$ endovenosa los días 2, 9 y 16 . Otros esquemas útiles son repetidos cada 21 días con un patrón de 5 días: cisplatino $20 \mathrm{mg} / \mathrm{m}^{2}$ en los días 1-5; etopósido $100 \mathrm{mg} / \mathrm{m}^{2}$ en los días 1 - 5 y bleomicina $15 \mathrm{mg} / \mathrm{m}^{2}$ (infusión de 12 horas) los días 1, 8 y 15 . O cisplatino $50 \mathrm{mg} / \mathrm{m}^{2}$ en los días 1 - 2; etopósido $165 \mathrm{mg} / \mathrm{m}^{2}$ en los días 1 - 3 y bleomicina $15 \mathrm{mg} / \mathrm{m}^{2}$ (infusión de 12 horas) los días 2,9 y $16(44,45)$.

El uso de paclitaxel con carboplatino como tratamiento de primera línea para tumores germinales y no germinales en embarazadas presenta el perfil de seguridad fetal más favorable con eficacia comprobada en el tratamiento de los tumores malignos de ovario. Los esquemas con bleomicina, en sustitución del etopósido, evitan el riesgo de tumores secundarios relacionados al tratamiento con etopósido (45).

El cuadro 1 muestra las complicaciones fetales más comunes asociadas al uso de agentes quimioterapéuticos.

Cuadro 1. Efectos tóxicos fetales de los quimioterapéuticos más utilizados en el tratamiento del cáncer de ovario durante el embarazo

\begin{tabular}{lcc}
\hline Fármaco & Daño fetal descrito & Observaciones \\
\hline Cisplatino & $\begin{array}{c}\text { Retraso en el desarrollo, pérdida de la audición, } \\
\text { neutropenia, pérdida del cabello, ventriculomegalia }\end{array}$ & \\
Carboplatino & Ninguno & \\
Paclitaxel & Estenosis pilórica, mielosupresión en neonatos & $\begin{array}{c}\text { Descripciones únicas } \\
\text { Etopósido }\end{array}$ \\
Bleomicina & $\begin{array}{c}\text { Pancitopenia, leucemia secundaria, } \\
\text { pérdida de la audición } \\
\text { Sindactilia }\end{array}$ & $\begin{array}{c}\text { Preocupación particular por } \\
\text { tumores secundarios }\end{array}$ \\
Vinblastina & Sindactilia, deformidades craneales & Más segura que el etopósido \\
\hline
\end{tabular}




\section{PLANIFICACIÓN DEL PARTO}

En estas pacientes, el parto debe planificarse a las 35 - 37 semanas, al menos 3 semanas después del final del último ciclo de quimioterapia, lo que evita la mielosupresión materna y fetal $(43$ - 45). El parto es posible, en especial si no se ha realizado algún procedimiento quirúrgico previo a este. La cirugía se puede posponer de forma segura luego de 6 8 semanas del parto. Si se realiza la interrupción quirúrgica del embarazo se debe aprovechar para evaluar o reclasificar la condición de la neoplasia maligna y sus posibles efectos locales.

\section{CONCLUSIONES}

El diagnóstico y tratamiento de los tumores de ovario durante el embarazo requieren instalaciones adecuadas, tanto en equipos como en preparación de equipos multidisciplinarios para el diagnóstico y manejo de neoplasias malignas. La ecografía y resonancia magnética son los métodos de elección en el diagnóstico de estos tumores. El momento óptimo para la cirugía es el segundo trimestre del embarazo y tanto la laparotomía como la laparoscopia son técnicas quirúrgicas seguras durante este periodo. El embarazo no afecta la evolución y pronóstico de los tumores malignos de ovario. Los esquemas de tratamiento no tienen efectos adversos significativos en la resultante perinatal, aunque el embarazo debe considerarse de alto riesgo.

\section{REFERENCIAS}

1. Gelder O, Carmona P, Pacheco F, Herrera V, Sarmiento P, Saldivia F, et al. Cáncer de mama y embarazo. Rev Venez Oncol. 2012; 24 (2): 148-151.

2. Mukhopadhyay A, Shinde A, Naik R. Ovarian cysts and cancer in pregnancy. Best Pract Res Clin Obstet Gynaecol. 2016; 33:58-72.

3. Yu C, Wang J, Lu W, Xie X, Cheng X, Li X. Analysis of adnexal mass managed during cesarean section. Adv Clin Exp Med. 2019; 28(4):447-452
4. Surampudi K, Nirmalan PK, Gundabattula SR, Chandran JB. Management of adnexal masses in pregnancy: our experience from a tertiary referral perinatal centre in South India. Arch Gynecol Obstet. 2015; 291(1):53-58.

5. Giuntoli RL, Vang RS, Bristow RE. Evaluation and management of adnexal masses during pregnancy. Clin Obstet Gynecol. 2006; 49(3):492-505.

6. Oehler MK, Wain GV, Brand A. Gynaecological malignancies in pregnancy: a review. Aust N Z J Obstet Gynaecol. 2003; 43(6):414-420.

7. Cavaco-Gomes J, Jorge Moreira C, Rocha A, Mota R, Paiva V, Costa A. Investigation and Management of Adnexal Masses in Pregnancy. Scientifica (Cairo) [Internet]. 2016 [consultada diciembre 2019]; 2016:3012802. Disponible en: https://pubmed.ncbi. nlm.nih.gov/27119043/

8. Gezginç K, Karataylı R, Yazıcı F, Acar A, Celik C, Capar M. Ovarian cancer during pregnancy. Int J Gynaecol Obstet. 2011; 115(2):140-143.

9. Blake EA, Kodama M, Yunokawa M, Ross MS, Ueda $\mathrm{Y}$, Grubbs BH, et al. Feto-maternal outcomes of pregnancy complicated by epithelial ovarian cancer: a systematic review of literature. Eur J Obstet Gynecol Reprod Biol. 2015; 186:97-105.

10. Blake EA, Carter CM, Kashani BN, Kodama M, Mabuchi S, Yoshino K, et al. Feto-maternal outcomes of pregnancy complicated by ovarian sex-cord stromal tumor: a systematic review of literature. Eur J Obstet Gynecol Reprod Biol. 2014; 175:1-7.

11. Kodama M, Grubbs BH, Blake EA, Cahoon SS, Murakami R, Kimura T, et al. Feto-maternal outcomes of pregnancy complicated by ovarian malignant germ cell tumor: a systematic review of literature. Eur J Obstet Gynecol Reprod Biol. 2014; 181:145-156.

12. Cordeiro CN, Gemignani ML. Gynecologic malignancies in pregnancy: Balancing fetal risks with oncologic safety. Obstet Gynecol Surv. 2017; 72(3):184-193.

13. Marret $\mathrm{H}$, Lhommé $\mathrm{C}$, Lecuru $\mathrm{F}$, Canis $\mathrm{M}$, Lévèque $\mathrm{J}$, Golfier $\mathrm{F}$, et al. Guidelines for the management of ovarian cancer during pregnancy. Eur J Obstet Gynecol Reprod Biol. 2010; 149(1):18-21.

14. Sayar H, Lhomme C, Verschraegen CF. Malignant adnexal masses in pregnancy. Obstet Gynecol Clin North Am. 2005; 32(4):569-593.

15. Telischak NA, Yeh BM, Joe BN, Westphalen AC, Poder L, Coakley FV. MRI of adnexal masses in pregnancy. AJR Am J Roentgenol. 2008; 191(2):364-370. 
16. Masselli G, Brunelli R, Casciani E, Polettini E, Bertini $\mathrm{L}$, Laghi $\mathrm{F}$, et al. Acute abdominal and pelvic pain in pregnancy: MR imaging as a valuable adjunct to ultrasound? Abdom Imaging. 2011; 36(5):596-603.

17. Kal HB, Struikmans H. Radiotherapy during pregnancy: fact and fiction. Lancet Oncol. 2005; 6(5):328-333.

18. Wakeford R. Childhood leukaemia following medical diagnostic exposure to ionizing radiation in utero or after birth. Radiat Prot Dosimetry. 2008; 132(2):166174.

19. Morice P, Uzan C, Gouy S, Verschraegen C, HaieMeder C. Gynaecological cancers in pregnancy. Lancet. 2012; 379(9815):558-569.

20. Aslam N, Ong C, Woelfer B, Nicolaides K, Jurkovic D. Serum CA125 at 11-14 weeks of gestation in women with morphologically normal ovaries. BJOG. 2000; 107(5):689-690.

21. Sarandakou A, Protonotariou E, Rizos D. Tumor markers in biological fluids associated with pregnancy. Crit Rev Clin Lab Sci. 2007; 44(2):151-178.

22. Barbosa CP, Souza AM, Bianco B, Christofolini D, Bach FA, Lima GR. Frequency of endometriotic lesions in peritoneum samples from asymptomatic fertile women and correlation with CA125 values. Sao Paulo Med J. 2009; 127(6):342-345.

23. Han SN, Lotgerink A, Gziri MM, Van Calsteren K, Hanssens M, Amant F. Physiologic variations of serum tumor markers in gynecological malignancies during pregnancy: a systematic review. BMC Med. 2012; 10:86.

24. Drapkin R, von Horsten HH, Lin Y, Mok SC, Crum CP, Welch WR, et al. Human epididymis protein 4 (HE4) is a secreted glycoprotein that is overexpressed by serous and endometrioid ovarian carcinomas. Cancer Res. 2005; 65(6):2162-2169.

25. Moore RG, Miller MC, Eklund EE, Lu KH, Bast RC Jr, Lambert-Messerlian G. Serum levels of the ovarian cancer biomarker HE4 are decreased in pregnancy and increase with age. Am J Obstet Gynecol [Internet]. 2012 [consultado diciembre 2019]; 206(4):349. e1-7. Disponible en: https://pubmed.ncbi.nlm.nih. gov/22301440/

26. Melo Â, Veríssimo R, Farinha M, Martins NN, Martins FN. Discriminative value of CA-125, HE4, Risk of Malignancy Index II (RMI-II) and Risk of Malignancy Algorithm (ROMA) in the differential diagnosis of pelvic masses: conclusions from a referral Centre in Portugal. J Obstet Gynaecol. 2018; 38(8):1140-1145.
27. Moore RG, Brown AK, Miller MC, Skates S, Allard WJ, Verch T, et al. The use of multiple novel tumor biomarkers for the detection of ovarian carcinoma in patients with a pelvic mass. Gynecol Oncol. 2008; 108(2):402-408.

28. Aggarwal P, Kehoe S. Ovarian tumours in pregnancy: a literature review. Eur J Obstet Gynecol Reprod Biol. 2011; 155(2):119-124.

29. Glanc P, Salem S, Farine D. Adnexal masses in the pregnant patient: a diagnostic and management challenge. Ultrasound Q. 2008; 24(4):225-240.

30. de Haan J, Verheecke M, Van Calsteren K, Van Calster B, Shmakov RG, Mhallem Gziri M, et al. Oncological management and obstetric and neonatal outcomes for women diagnosed with cancer during pregnancy: a 20year international cohort study of 1170 patients. Lancet Oncol. 2018; 19(3):337-346.

31. Amant F, Berveiller P, Boere IA, Cardonick E, Fruscio R, Fumagalli M, et al. Gynecologic cancers in pregnancy: guidelines based on a third international consensus meeting. Ann Oncol. 2019; 30(10):16011612.

32. Marret H, Lhommé C, Lécuru F, Canis M, Léveque J, Golfier F, et al. [French recommendations for ovarian cancer management during pregnancy]. Gynecol Obstet Fertil. 2009; 37(9):752-763. Francés.

33. Amant F, Halaska MJ, Fumagalli M, Dahl Steffensen $\mathrm{K}$, Lok C, Van Calsteren K, et al. Gynecologic cancers in pregnancy: guidelines of a second international consensus meeting. Int J Gynecol Cancer. 2014; 24(3):394-403.

34. Han SN, Verheecke M, Vandenbroucke T, Gziri MM, Van Calsteren K, Amant F. Management of gynecological cancers during pregnancy. Curr Oncol Rep. 2014; 16(12):415.

35. Grimm D, Woelber L, Trillsch F, Keller-v Amsberg G, Mahner S. Clinical management of epithelial ovarian cancer during pregnancy. Eur J Cancer. 2014; 50(5):963-971.

36. Committee on Obstetric Practice and the American Society of Anesthesiologists. Committee Opinion No. 696: Nonobstetric Surgery During Pregnancy. Obstet Gynecol. 2017; 129(4):777-778.

37. Reginald PW, Beard RW, Chapple J, Forbes PB, Liddell HS, Mowbray JF, et al. Outcome of pregnancies progressing beyond 28 weeks gestation in women with a history of recurrent miscarriage. Br J Obstet Gynaecol. 1987; 94(7):643-648. 
38. Bates SM, Greer IA, Middeldorp S, Veenstra DL, Prabulos AM, Vandvik PO. VTE, thrombophilia, antithrombotic therapy, and pregnancy: Antithrombotic therapy and prevention of thrombosis, 9th ed: American College of Chest Physicians Evidence-Based Clinical Practice Guidelines. Chest [Internet]. 2012 [consultado diciembre 2020]; 141(2 Suppl):e691Se736S. Disponible en: https://pubmed.ncbi.nlm.nih. gov/22315276/

39. Brewer M, Kueck A, Runowicz CD. Chemotherapy in pregnancy. Clin Obstet Gynecol. 2011; 54(4):602-618.

40. Smith ER, Borowsky ME, Jain VD. Intraperitoneal chemotherapy in a pregnant woman with ovarian cancer. Obstet Gynecol. 2013; 122(2 Pt 2):481-483.

41. De Giorgi U, Casadei C, Bergamini A, Attademo L, Cormio G, Lorusso D, et al. Therapeutic Challenges for Cisplatin-Resistant Ovarian Germ Cell Tumors. Cancers (Basel). 2019; 11(10):1584.

42. El-Lamie IK, Shehata NA, Abou-Loz SK, El-Lamie KI. Conservative surgical management of malignant ovarian germ cell tumors: the experience of the Gynecologic Oncology Unit at Ain Shams University. Eur J Gynaecol Oncol. 2000; 21(6):605-609.
43. Skrzypczyk-OstaszewiczA, Rubach M. Gynaecological cancers coexisting with pregnancy - a literature review. Contemp Oncol (Pozn). 2016; 20(3):193-198.

44. Ngu SF, Ngan HY. Chemotherapy in pregnancy. Best Pract Res Clin Obstet Gynaecol. 2016; 33:86-101.

45. Van Calsteren K, Verbesselt R, Ottevanger N, Halaska M, Heyns L, Van Bree R, et al. Pharmacokinetics of chemotherapeutic agents in pregnancy: a preclinical and clinical study. Acta Obstet Gynecol Scand. 2010; 89(10):1338-1345.
Recibido: 20 de marzo de 2020

Aprobado: 22 de mayo de 2020 